\title{
Variance of vegetation coverage and its sensitivity to climatic factors in Irtysh River basin
}

\author{
Feifei Han ${ }^{1,2}$, Junjie Yan ${ }^{\text {Corresp., } 3}$, Hong-bo Ling ${ }^{\text {Corresp. } 1}$ \\ ${ }^{1}$ State Key Laboratory of Desert and Oasis Ecology, Xinjiang Institute of Ecology and Geography, Chinese Academy of Sciences (CAS), Urumqi, Xinjiang, \\ China \\ 2 College of Water and Architectural Engineering, Shihezi university, Shihezi, Xinjiang, China \\ 3 Institute of resources and ecology, Yili Normal University, Yining, China \\ Corresponding Authors: Junjie Yan, Hong-bo Ling \\ Email address: yan3550@sina.com, linghb@ms.xjb.ac.cn
}

Background. Climate change is an important factor driving vegetation changes in arid areas. Identifying the sensitivity of vegetation to climate variability is crucial for developing sustainable ecosystem management strategies. Irtysh River is located in the westerly partition of China, and its vegetation cover is more sensitive to climate change. However, previous studies rarely studied the changes in the vegetation coverage of the Irtysh River and its sensitivity to climate factors from a spatiotemporal perspective.

Methods. we adopted a vegetation sensitivity index (VSI) based on remote sensing datasets of high temporal resolution to study the sensitivity of vegetation to climatic factors in Irtysh River basin, then reveal the driving mechanism of vegetation cover change.

Results. The results show that $88.09 \%$ of vegetated pixels show an increasing trend in vegetation coverage, and the sensitivity of vegetation to climate change presents spatial heterogeneity. Sensitivity of vegetation increases with the increase of coverage. Temperate steppe in the northern mountain and herbaceous swamp and broadleaf forest in the river valley, where the normalized difference vegetation index (NDVI) is the highest, show the strongest sensitivity, while the desert steppe in the northern plain, where the NDVI is the lowest, shows the strongest memory effect (or the strongest resilience). Relatively, the northern part of this area is more affected by a combination of precipitation and temperature, while the southern plains dominated by desert steppe are more sensitive to precipitation. Central river valley dominated by herbaceous swamp is more sensitive to temperature-vegetation dryness index (TVDI). This study underscores that the sensitivity of vegetation cover to climate change is spatially differentiated at the regional scale. 
1 Variance of vegetation coverage and its sensitivity to climatic factors in

2 Irtysh River basin

3 Feifei Han ${ }^{1,2}$, Junjie Yan ${ }^{3}$, Hongbo Ling ${ }^{1}$

4

$5{ }^{1}$ State Key Laboratory of Desert and Oasis Ecology, Xinjiang Institute of Ecology and

6 Geography, Chinese Academy of Sciences (CAS), Urumqi, Xinjiang, China

$7 \quad{ }^{2}$ College of Water and Architectural Engineering, Shihezi university, Shihezi, Xinjiang, China

$8{ }^{3}$ Institute of resources and ecology, Yili Normal University, Yining, Xinjiang, China

Corresponding Author:

Email address: yan3550@sina.com (J. Yan); linghb@ms.xjb.ac.cn (H. Ling).

\section{Abstract}

Background. Climate change is an important factor driving vegetation changes in arid areas. Identifying the sensitivity of vegetation to climate variability is crucial for developing sustainable ecosystem management strategies. Irtysh River is located in the westerly partition of China, and its vegetation cover is more sensitive to climate change. However, previous studies rarely studied the changes in the vegetation coverage of the Irtysh River and its sensitivity to climate factors from a spatiotemporal perspective.

Methods. we adopted a vegetation sensitivity index (VSI) based on remote sensing datasets of high temporal resolution to study the sensitivity of vegetation to climatic factors in Irtysh River basin, then reveal the driving mechanism of vegetation cover change.

Results. The results show that $88.09 \%$ of vegetated pixels show an increasing trend in vegetation coverage, and the sensitivity of vegetation to climate change presents spatial heterogeneity. Sensitivity of vegetation increases with the increase of coverage. Temperate steppe in the northern mountain and herbaceous swamp and broadleaf forest in the river valley, where the normalized difference vegetation index (NDVI) is the highest, show the strongest sensitivity, while the desert steppe in the northern plain, where the NDVI is the lowest, shows the strongest memory effect (or the strongest resilience). Relatively, the northern part of this area is more affected by a combination of precipitation and temperature, while the southern plains dominated by desert steppe are more sensitive to precipitation. Central river valley dominated by herbaceous swamp is more sensitive to temperature-vegetation dryness index (TVDI). This study underscores that the 


\section{Introduction}

41 Vegetation covers nearly three-quarters of the land surface(Sarkar \& Kafatos 2004), which is the main body of

42 the terrestrial ecosystem(Cramer \& Leemans 1993), and plays an important role in linking the soil and atmosphere

43 through energy and mass transport(Deng et al. 2017). In the context of global climate change, vegetation is affected

44 by climate change and becomes the sufferers of climate change, acting as an "indicator" in global climate change research(Piao et al. 2006). The changes vegetation also have feedback effect on climate change (Liu et al. 2006; Sun et al. 2018). Therefore, monitoring and mapping the sensitivity of vegetation to current climate variability is crucial for projecting future vegetation dynamics and developing sustainable ecosystem management strategies.

Investigating the responses of vegetation to short-term climate anomalies is of great significance to mitigate the ecological, economic, and social consequences of future climate change (Huete \& Alfredo 2016). Much current understanding of vegetation's respond to climate change is based on changes in mean climate state (Mearns et al. 1997; Thomas et al. 2004). We consider this mean state can only represent changes in the equilibrium state (e.g. due to overgrazing or long-term successional cycles (Clifford et al. 2011)) instead of anomalies resulting from shortbefore we analyze the sensitivity of vegetation to climate variability and that is how to describe vegetation sensitivity in a quantitative way. There are several ways defining the vegetation's sensitivity to climate variability. anomaly occurs(You et al. 2018) or the degree to which a system changes after a disturbance(Li et al. 2018). In this study, vegetation's sensitivity is defined as the magnitude of vegetation response at the moment of the climate anomaly(Tilman 1996). Additionally, Moulin S et al. (Moulin et al. 1997) found that due to the relatively slow

62 growth of vegetation, the response of vegetation to climate change often lags, therefore vegetation growth depends 63 both on current disturbances and the residual effects of past climate conditions. We called this phenomenon the vegetation memory effect and it could be described as the persistence of trends in temporal changes of ecosystem 
67 Since the 1970 s, the development of satellite remote sensing technology has made it possible for a human to 68 conduct macro dynamic monitoring of earth vegetation from space (Pettorelli et al. 2014; Weng 2002). In the past 69 decades, there has been an increase in the availability of satellite data measuring climate and other ecologically

70

71

72

73

74

75

76

77

relevant variables(Kerr \& Ostrovsky 2003). These data offer opportunities to characterize ecosystem sensitivity at high spatial resolution. Based on satellite-derived images, Seddon et al. (Seddon et al. 2016) present recently a novel method to identify ecosystem sensitivity and memory effect to short-term climate variability by developing a vegetation sensitivity index (VSI) that explores the linkage between variability in vegetation productivity (defined as enhanced vegetation index, EVI) and three climate variables (namely air temperature, water availability, and cloudcover) on monthly time scales. The vegetation sensitivity index is a useful metric to quantitatively assess the sensitivity of different ecosystems to climate variability (Huete 2016; Willis et al. 2018) and simultaneously takes into account short-term climate effects and vegetation 'memory effect'.

Drylands (including arid and semi-arid regions) occupy over $41 \%$ of the global land surface area and are inhabited by $>2$ billion people (Safriel et al. 2020). Temperature and precipitation are usually the main climatic factors affecting vegetation activities ( $\mathrm{Li}$ et al. 2015; Seddon et al. 2016; Yang et al. 2015). Arid area is usually characterized by rare precipitation and high temperatures, and both water and heat have important effects on vegetation growth, which makes ecosystems in arid and semi-arid regions are more vulnerable to climatic disturbances(Rotenberg \& Yakir 2010). Except for the direct but rare precipitation, soil water supplied by meltwater from ice and snow in mountainous areas is primarily the main water source for vegetation growth in plain areas, especially for forests and wetlands in river valleys. Thus, moisture of the soil is also a profound factor affecting vegetation activities in the arid area. Compared to cloud-cover, soil moisture is far more influential on vegetation in the arid area. TVDI characterizes the changes between vegetation index and land surface temperature, and is an important indicator reflecting the soil moisture status(Grassini et al. 2010; Sandholt et al. 2002). So, we substituted the climatic factor of cloud-cover in Seddon's model by TVDI in our study. Additionally, among the all kinds of vegetation indexes, NDVI is the most widely used and also is one of the earliest proposed. No other vegetation index is capable to compare with NDVI in its widely use. NDVI has long been applied in monitoring vegetation dynamics(Fensholt et al. 2009; Slayback et al. 2003)(, changes of vegetation phenology(Jeong et al. 2011; Ludeke et al. 1996) and assessing land degradation(Oba et al. 2001; Thiam 2003). NDVI has also been used as basic parameter in modeling of vegetation productivity(Schloss et al. 1999), terrestrial evapotranspiration(Maselli et al. 2014; Yang

Peer) reviewing PDF | (2020:11:55104:1:2:NEW 18 Mar 2021) 
$95 \&$ Wang 2011) and predicting yield of crops (Kastens et al. 2005; Mkhabela et al. 2011).Therefore, we chose NDVI

96 to characterize vegetation coverage. Irtysh River basin is located in the arid and semi-arid region in the northwest of

97 China where water resources are scarce, and it is an important water source in this area and plays an important role

98 in regional economic development and ecological protection(Ye \& Bai 2014). The Irtysh River is an international

99 river, which has complicated interests with neighboring countries in the international distribution of water resources,

100 prevention and control of water pollution, ecological maintenance and international regional cooperation. The

101 existing research(Huang et al. 2013a; Huang et al. 2012) showed that Irtysh River basin is sensitive to environmental

102 change. Therefore, we selected this area as our study area and analyzed the changes of its natural vegetation and

103 climate, and further identified the spatial differentiation in the sensitivity of the vegetation to climate changes, which

104 are of valuable reference significance for dealing with climate change and maintaining ecological stability of the

105 basin in the future.

106 Based on the remote sensing data, we used the Mann-Kendall non-parametric rank statistical test to analyze the 107 vegetation dynamic and then calculated VSI to discuss the vegetation sensitivity. In this study, our aims are to (1)

108 map the spatial trends of vegetation cover in 2000-2018; (2) investigate the controlling factors of vegetation

109 sensitivity and resilience in Irtysh River basin.

\section{Materials \& Methods}

\section{Study area}

112 Irtysh River basin is in the arid and semi-arid area of northwest China where water resources are scare

$113\left(45^{\circ} 40^{\prime} \sim 48^{\circ} 27^{\prime} \mathrm{N}, 85^{\circ} 30^{\prime} \sim 91^{\circ} 2^{\prime}\right.$ E, Fig.1). The region relates to the Altai Mountains in the north and

114 crosses into the northern edge of the fold system of the Junggar Basin in the south and is adjacent to Mongolia,

115 Kazakhstan, and other countries in the East and West. A typical temperate continent cold climate(Ju et al. 2015;

116 QiangJi \& Wu 2017) dominates this area, with annual mean temperature ranging from $3.6^{\circ} \mathrm{C}$ to $3.9^{\circ} \mathrm{C}$, and the cold

117 air activities are frequent in winter and spring in mountainous areas, forming disasters such as blizzards,

118 snowstorms, and avalanches now and then. The annual mean precipitation is about $217.1 \mathrm{~mm}$, the precipitation

119 increases gradually alone the increase of elevation, yet the northwest part is wetter than the southeast part in general(Shen et al. 2007). The vegetation in the study area is mainly desert meadow and grassland, accounting for 
122 broad-leaved forest or shrub scattered in or near the swamp area. As growth of the crops are managed by farmers,

123 which disturbs the regulation of climate, we excluded farm and area of non-vegetation in our study.

124

125

126

127

128

129

130

131

132

133

134

135

136

137

138

139

140

141

142

143

144

145

146

147

148

149

150

\section{Data source and pre-processing Meteorological Data}

Monthly precipitation and air temperature datasets of 72 meteorological stations in the territory of Xinjiang province of China, where the study area located, were collected from the China Meteorological Data Service Center (CMDC). The datasets cover the period of 2000-2018. These 72 meteorological stations are unevenly distributed in space, and interpolation is the reliable and common practice to obtain continuous surface data(Guo et al. 2020). Both precipitation and air temperature are strongly affected by topography. The interpolation of Australian National University Spline or Anusplin, based on the thin plate spline algorithm, is primarily the first choice when interpolation is necessary, as it takes the effect of topography into account (Hutchinson \& Xu. 2013). A. Dewi Hartkamp et al.(1999) and Claire H et al.(2001) have long confirmed the superiority of the thin plate spline over other algorithms, such as inverse distance weighting method or kriging. Datasets of Climatic Research Unit (CRU), WorldClim 1 and WorldClim 2 are all produced using Anusplin, and the China Meteorological Administration also used the Anusplin in producing the daily gridded dataset(Zhao et al. 2014). Therefore, we also applied the Anusplin to interpolate our raster surface of precipitation and air temperature. The pixel size was set to $250 \mathrm{~m}$ in the interpolating to keep in line with that of the NDVI images. Among the 72 meteorological stations, 7 are in or at the border of the study area (Fig.1)(Jarvis \& Stuart 2001).

\section{Remote sensing Data}

Moderate Resolution Imaging Spectroradiometer (MODIS) NDVI product (MOD13Q1) covering the period of 2000-2018 were used to determine the variation of vegetation cover. This MOD13Q1 product was 16-day NDVI synthetic data using the Maximum Value Composite (MVC) method, and its pixel size is about $250 \mathrm{~m} \times 250 \mathrm{~m}$.

Time series NDVI images are easily tarnished by noise signal received by the satellite sensors due to effects of the atmosphere, clouds, geometric misregistration or many other uncontrollable factors(Goward et al. 1991). In hopes to eliminate the noise and built high-quality NDVI time series, scholars have developed many kinds of smoothing algorithms, such as the SPLINE-curve fitting, double logistic functions, Savitzky-Golay filter, harmonic analysis of time series and so on(Cai et al. 2017; Pan et al. 2017). Among these smoothing algorithms, both Pan et al. (2017) and Cai et al.(2017) have confirmed the Savitzky-Golay filter's superiority. We followed the recommendation of 
151 Pan et al. and Cai et al. and performed the Savitzky-Golay filtering on our NDVI images to obtain high-quality

152 NDVI time series. And then we applied MVC to NDVIs covering every year of the period of $2000-2018$ to get

153 NDVI that reflects the yearly highest growing level of vegetation, namely NDVI at yearly time scale. We used

154 yearly maximum NDVI to analyze the inter-annual dynamics of vegetation. We also applied MVC to NDVIs

155 covering every month of the period of 2000-2018 to get the monthly NDVI.

156 Temperature Vegetation Dryness Index (TVDI) can be used to characterize the degree of soil drought. This study

157 mainly uses the method proposed by Sanholt I et al. and Yao et al. (Sandholt et al. 2002; Yao et al. 2004) to

158 calculate TVDI. TVDI is a combination of vegetation index (VI) and land surface temperature (LST). Monthly

159 TVDI were calculated using the MODIS NDVI and the 8-day composite MODIS temperature product (MOD11A2).

160 The MOD11A2 product includes LST images of day and night, with a pix size about $1000 \mathrm{~m} \times 1000 \mathrm{~m}$. The day LST

161

162

163

164

165

166

167

168

169

170

171

172

173

174

175

176

177

178 was used in the study. Every 4 LST images covering the whole corresponding month were averaged to get the monthly LST time series data, and the pixel size was resampled to $250 \mathrm{~m} \times 250 \mathrm{~m}$ with the nearest-neighbor resampling algorithm(Christman \& Rogan 2012; Khan et al. 1995) integrated in toolbox of ArcGIS software to match that the of NDVI images.

It is well known that there are ubiquitous data gaps in LST datasets because of non-overlapping satellite orbits, cloud contamination, instrumental malfunction (Chen et al. 2011; Hu et al. 2014) and interpolation methods are usually applied to fill the data gaps (Cai et al. 2017; Garcia 2010). Garcia (2010) have developed a fast and robust smooth regression algorithm that combines the Discrete Cosine Transform (DCT) and the Penalized Least Square approach (PLS) together with the Generalized Cross-Validation (GCV) criterion to fill data gaps. Liu et al. (2010) tested and applied Garcia's method on the reconstruction of the MODIS LST datasets covering the three continents of South America, Africa and Asia, and confirmed its capability and robustness. We applied this method in our data processing to get a high quality LST dataset and further guarantee our TVDI dataset can reflect the drought of soil more accurately.

\section{Mann-Kendall non-parametric rank statistical test}

When using Mann-Kendall non-parametric test(Kendall 1990; Mann 1945) to test the possible trends of climatic elements and time series, we assume that $\mathrm{H} 0$ indicates that the time series $(\mathrm{x} 1, \mathrm{x} 2, \ldots, \mathrm{xn})$ are independent of the data sample, and there is no obvious trend; Assuming that $\mathrm{H} 1$ is a bilateral test, the distribution of $\mathrm{xi}$ and $\mathrm{xj}$ are different for all $\mathrm{i}, \mathrm{j}(\mathrm{i} \neq \mathrm{j})$, the calculation formula of the statistical variable $\mathrm{S}$ of the test is as follows:

PeerJ reviewing PDF | (2020:11:55104:1:2:NEW 18 Mar 2021) 


$$
S=\sum_{i=1}^{n-1} \sum_{k=i+1}^{n} \operatorname{Sgn}\left(x_{k}-x_{i}\right)
$$

180

181

182

Among them,

$\mathrm{S}$ is normal distribution, the mean is 0 , and the variance is as follows:

$$
\operatorname{Sgn}((\theta))=\left\{\begin{array}{cc}
1 & \theta>0 \\
0 & \theta=0 \\
-1 & \theta<0
\end{array}\right.
$$

$$
\operatorname{Var}(s)=\left[n(n-1)(2 n+5)-\sum_{t} t(t-1)(2 t+5)\right] / 18
$$

Where $t$ is the width of each unit. When $n>10$, Zc converges to a standard normal distribution and can be calculated by the following formula.

188

189

190

191

192

193

194

$$
Z_{c}=\left\{\begin{array}{cc}
\frac{S-1}{\sqrt{\operatorname{Var}(S)}} & S>0 \\
0 & S=0 \\
\frac{S+1}{\sqrt{\operatorname{Var}(S)}} & S<0
\end{array}\right.
$$

\section{(4)}

At a given $\alpha$ confidence level, when $|\mathrm{Zc}|>1.96$, the changing trend reaches a significant level, $|\mathrm{Zc}|<1.96$, the changing trend is not Significant; $\mathrm{Zc}>0$, indicating that the changing trend is increasing, and $\mathrm{Zc}<0$, it is decreasing.

Theil-Sen median trend analysis(Atta ur \& Dawood 2017; Coen et al. 2020) could be used to quantify the trend of time series data, and its calculation formula is as follows:

$$
\beta=\operatorname{Median}\left(\frac{x_{i}-x_{j}}{i-j}\right)
$$

In the formula, $1<\mathrm{j}<\mathrm{i}<\mathrm{n}, \beta$ means slope, a positive value means "uptrend", and a negative value means "downtrend".

\section{Identifying the sensitivity of vegetation to climate variability}

The VSI is a novel and empirical metric developed by Seddon et al. (2016) that can quantify the sensitivity of different vegetation areas to climate variability (Huete 2016; Willis et al. 2018). In this study, we tailored the empirical methodology to identify vegetation sensitive to climate variability on the Irtysh River basin. 
201

202

203

204

205

206

207

208

209

210

211

212

213

214

215

216

217

218

219

220

221

222

223

224

225

226

Firstly, for the climatic variables, we employed temperature, precipitation, and TVDI, instead of three climate variables as in Seddon et al. (2016). Furthermore, we included the one-month-lagged NDVI monthly data as a fourth variable in the regression to investigate the potential influence of memory effects driving vegetation dynamics.

Secondly, any month with a mean NDVI of $<0.1$ were excluded to reduce the potential impact of noisy data at low NDVI values, which are attributed to areas with extremely sparse or inexistent vegetation cover(Zhang 2015; Zhu et al. 2019). And to remove seasonal component underlying monthly time series, we de-trended the monthly data and then we standardized the de-trended data utilizing the Z-score standardization formula:

$$
Z_{i, j}=\frac{x_{i, j}-\bar{x}_{j}}{\sigma_{j}}
$$

Where $\mathrm{xi}, \mathrm{j}$ is the detrended data in the $\mathrm{jth}$ month of the ith year, $\mathrm{xj}$ and $\sigma_{j}$ are the mean and standard deviation of the variable $\mathrm{x}$ in the $\mathrm{jth}$ month of all years, respectively.

Thirdly, in this study, the sensitivity of vegetation to climate variability on the Irtysh River basin was primarily calculated using AR1 multiple linear regression approach in each pixel, as follows:

$$
N D V I_{t}=\alpha \times N D V I_{t-1}+\beta \times T e m_{t}+\gamma \times \operatorname{Pre}_{t}+\delta \times T V D I_{t}+\varepsilon_{t}
$$

Where $N D V I_{t}$ is the standardized NDVI at time t, $N D V I_{t-1}$ is the standardized NDVI anomaly at time t-1,Tem ${ }_{t}$, $\operatorname{Pre}_{t}$ and $T V D I_{t}$ are the standardized temperature, precipitation, and TVDI at time t, respectively. $\varepsilon_{t}$ is the residual term at time t, and $\alpha, \beta, \gamma$, and $\delta$ are coefficients for temperature, precipitation, TVDI and $N D V I_{t-1}$ of each pixel, respectively. Each of $\alpha, \beta, \gamma$, and $\delta$ is a metric of ecosystem stability (Table 1; (De Keersmaecker et al. 2015)). Compared to the correlation coefficient which can only indicate whether the ecosystem responds to climate variability, the regressive coefficient can further reflect the response magnitude.

Fourthly, to eliminate the effects of co-linearity between four climate variables, the principal components regression (PCR) was also applied within each pixel to quantify the relative importance of each variable driving variations in the monthly NDVI (Seddon et al. 2016). The principal components that had significant relationships with climate $(\mathrm{p}<0.1)$ were selected, and we subsequently multiplied the loading scores of each variable by the PCR coefficients. The product scores were summed to estimate the relative importance of each variable in driving monthly changes in NDVI, which provided an empirical approach for mapping the relative importance of climate on vegetation change (climate weights).

Peer] reviewing PDF | (2020:11:55104:1:2:NEW 18 Mar 2021) 

of any of the climate coefficient values), to be used for calculations of vegetation sensitivity. To estimate the variations of both the climate variables and NDVI on these time series, we used the residuals of a linear model fitted variability and each of the climate variables. Each ratio was then weighted according to the importance of the climate variable to EVI variability by multiplying it by the value of the regression coefficient (climate weights). period of study.

$$
V S I=\text { Tem }_{\text {wei }} \times \text { Tem }_{\text {sens }}+\text { Pre }_{\text {wei }} \times \text { Pre }_{\text {sens }}+T V D I_{w e i} \times T V D I_{\text {sens }}
$$
found in Seddon et al. (2016).

\section{3}

\section{Results}

\section{Variances in vegetation cover and climatic factors} increased from the southern plain to the northern mountain area. Vegetation in the plain area, except for the river accounting for $7.89 \%$ of the vegetated pixels. 
256

257

258

259

260

261

262

263

264

265

266

267

268

269

270

271

272

273

274

275

276

277

278

279

280

281

282

283

dominated by desert meadow and grassland (Fig.2b). 17.81\% of the vegetated pixels showed a significant increasing trend, and are mainly located in the western part and central part in the south. Areas with NDVI showing decreasing trend are sparsely distributed in the northern piedmont area and part of the west end. For the changing rate $\beta$, the proportion of pixels with $\beta>0$ reached $89.04 \%$. NDVI of areas in the central valley, mountains in the east and central plains of the south showed the most rapid increase $(\beta>0.002)$, the proportion is $26.79 \%$. The increasing rate was relatively $\operatorname{low}(0<\beta<0.001)$ for the plain of the east and southwest, and the central mountain of the south, which occupied $62.26 \%$ of the vegetated pixels.

Climatic factors are the main driving forces for variation of vegetation. Therefore we performed Mann-Kendall tests on precipitation, temperature and TVDI data to reveal their changing trends separately. The results (Fig.4) showed that the precipitation and temperature in the study area showed a non-significant increasing trend from 2000 to 2018 , meaning whether condition in the study area were getting warmer and wetter. Relatively, TVDI in the study area showed a non-significant decreasing trend from 2000 to 2018 , indicating that the soil moisture in the study area is gradually increasing. The increased precipitation and temperature and decreased TVDI indicate that the hydrothermal conditions and soils required for vegetation growth in the study area have been greatly improved in the past 19 years, which promoted the increasing of the NDVI for the whole study area.

\section{Vegetation Memory effects}

Vegetation memory effects have been widely reported in water-limited ecosystems at various time-scales (Los et al. 2006; Schwinning et al. 2004). Seddon et al. found that a one-month lag provided the best explanatory power for vegetation responses to variability on short-term timescales. Therefore, we included the one-month-lagged NDVI monthly data as a fourth variable in the regression to investigate the potential influence of memory effects driving vegetation dynamics. The areas with high variance explained by the $\mathrm{t}-1$ variable in the AR1 model, indicating systems where memory effects play a more important role than contemporary climate conditions in determining vegetation cover (Fig.5). The larger the t-1 coefficient weight (that is, coefficient $\alpha$ ), the stronger the memory effect, and the weaker the sensitivity (with lower VSI).

Vegetation showed strong memory effects $(\alpha>0.4)$ across almost the whole study area (Fig.5), especially in some parts of the eastern plain where the coefficient reached more than 0.6 , and the area with $\alpha>0.6$ accounted for $27.27 \%$ of the vegetated pixels in the study area. Coefficient $\alpha$ of areas in the northwest, the border of the east and river valley in the middle is relatively small $(\alpha<0.4)$, indicating weaker memory effects, and the areas proportion is 
$28420.60 \%$. Yet for most parts of the study area, the coefficient $\alpha$ is about $0.4-0.6$, and the area proportion reached $28552.13 \%$. Notably, vegetation with big NDVI showed weak memory effect in general, such as the herbaceous swamp 286 and broadleaf forest in the river valley and grassland in the mountain area of the north border. In contrast, the desert 287 grass in the plain area showed strong memory effect.

288 As shown in Fig.6, the memory effect tends to change along the gradient of NDVI and climatic factors. To 289 identify the controlling factors for vegetation memory effects, we regressed $\alpha$ (t-1 coefficient weight) against three 290 climatic factors (precipitation, temperature, and TVDI) and vegetation cover (defined as NDVI). And considering 291 the hydrothermal conditions required for vegetation growth, we selected the mean NDVI, mean precipitation, mean 292 temperature, and mean TVDI of the growing season (GS) to participate in the regression. The results showed that 293 vegetation memory effects $(\alpha)$ decreased logarithmically as NDVI increased $\left(\mathrm{R}^{2}=0.67, \mathrm{P}<0.05\right.$, Fig.6a). Relatively, 294 vegetation memory effects $(\alpha)$ increased logarithmically as TVDI increased $\left(R^{2}=0.407\right.$, $P<0.05$, Fig.6d).

295 Specifically, vegetation memory effects $(\alpha)$ presented a quadratic parabola relationship with both precipitation $296\left(\mathrm{R}^{2}=0.202, \mathrm{P}<0.05\right.$, Fig.6b) and temperature $\left(\mathrm{R}^{2}=0.155, \mathrm{P}<0.05\right.$, Fig.6c $)$.

\section{Vegetation sensitivity to climatic variables}

298 Compared to strong memory effects, the VSI in the study area is rather low, with $60.69 \%$ of the vegetated pixels

299 where VSI is less than 30 (Fig.7b). Spatially, areas of big VSI (VSI>30) generally overlap that of weak memory 300 effects $(\alpha<0.4)$, such as the grassland in the north border and herbaceous swamp and broadleaf forest in the river 301 valley, indicating that areas with higher NDVI usually shows weaker memory effects and higher sensitivity to 302 climate variability over the past 19 years. Areas of the desert plain show low sensitivity (VSI $>30$ ) to climate 303 variability, and overlap the areas of strong memory effects $(\alpha>0.4)$.

304 The relative importance of three climate variables (temperature, precipitation, and TVDI) to vegetation sensitivity 305 also displayed clear spatially heterogeneity across the study area (Fig.8). Most areas are more sensitive to 306 precipitation, mainly distributed in the southern and central plains dominated by desert meadow. While variation in 307 vegetation cover (defined as NDVI) of the southeastern areas were mainly affected by a combination of precipitation 308 and temperature, and the northern part of this area is affected by a combination of TVDI and temperature. 309 Additionally, vegetation cover in the northwest areas was mainly driven by precipitation and TVDI. Remarkably,

310 the central river valley dominated by herbaceous swamp was more sensitive to TVDI. And the mountain areas with 311 higher elevations in the north are more sensitive to both temperature and precipitation. 


\section{Discussion}

314 Disentangling the driving factors for variations in vegetation cover

315 Irtysh River basin is located in arid and semi-arid region. Scarce precipitation and high temperature lead to large

316 evapotranspiration and low soil water storage in this area, which is not conducive to the growth of vegetation,

317 especially in the low land of the southern plain. Therefore, most part of the study area is dominated by desert

318 vegetation. However, as the altitude increases, the precipitation increases and temperature decreases (Navarro et al.

319 2020), and this relieves the severe climatic restrictions. So, grassland in areas of high altitude, mainly the mountain

320 areas in the north, is well developed and the vegetation coverage is also high $(0.4<\mathrm{NDVI}<0.6)$. The river valley can

321 rely on the rivers to supply ample water required for vegetation growth, so the herbaceous swamp and broadleaf

322 forest with the highest NDVI (NDVI $>0.6$ ) are well developed in this area.

323 The results of the Mann-Kendall trend test of climatic factors show that the temperature and precipitation in the

324 study area showed an increasing trend from 2000 to 2018, and the TVDI showed a decreasing trend. This is 325 consistent with the findings of Huang et al (Huang et al. 2013b). The analysis of the results indicate that the 326 hydrothermal and soil conditions required for vegetation growth in the Irtysh River basin have been greatly 327 improved. However, with the change of altitude gradient and climatic factors, the variation trend $(\mathrm{Zc})$ and rate $(\beta)$ of

328

329

330

331

332

333

334

335 vegetation cover show obvious spatial heterogeneity. The increase of rainfall brings abundant water resources to the desert plain area in the southern study area, improves the available moisture content of the local soil, thus promoting the absorption of plant nutrients, which is conducive to the improvement of water utilization rate of plants, and greatly promotes the growth of vegetation and the increasing rate of local vegetation cover. The vegetation growth in the central valley, which is dominated by herbaceous marshes, mainly depends on rivers to supply groundwater to meet the requirements of soil moisture. In recent years, with the continuous strengthening of national ecological protection, the ecological water volume of Irtysh River has been well guaranteed (Yang et al. 2012; Ye \& Bai 2014), which can timely recharge the groundwater aquifer in the valley area, thus increasing the soil moisture in this area, and TVDI presents a decreasing trend. In addition to the supply of rainfall, the vegetation cover in this region showed a significant trend of increase from 2000 to 2018, and the increase rate was also very fast. Studies (Jiang et al. 2017) have shown that the impact of air temperature on vegetation growth is topographically different. In the central river valley where it is relatively wet, elevated temperature can promote plant photosynthetic activity and thus lead to a positive response of vegetation growth. In the northern study region where it is relatively dry, increase 
341 of temperature can intensify the water deficit through elevated evaporation and thus causes a negative response of

342 NDVI. In particular, although the climatic conditions in the study area showed a pattern of improvement, the impact

343 of human activities on vegetation cover could not be ignored. The research results of Yang et al.(Han et al. 2013)

344 showed that from 1990 to 2010, the overall landscape pattern of the Irtysh River Basin tended to be fragmented,

345 with serious spatial heterogeneity, which was increasingly affected by human activities over time. The research

346 results of this paper also reflect this phenomenon. The regions with different elevations have different responses to

347 the same climatic factors.

\section{Environmental impacts on vegetation memory effect during growth season}

349 We can see in Fig.5 that areas with the strongest memory effects are generally located in the desert pain of the

350

351

352

353

354

355

356

357

358

359

360

361

362

363

364

365

366

367

368

369 southeast, where the NDVI is the smallest and the drought the strongest. And areas with weakest memory effects is gathered in the mountain areas of the north and river valleys in the middle, where the NDVI is the biggest and the drought the weakest. This character in the matching between the memory effects and both of NDVI and drought can also be seen in the clean decreasing trend of metric $\alpha$ along with the increasing NDVI and also the increasing trend with the increasing TVDI (Fig.6a, 6d). Vegetation in the arid area or desert are usually characterized by their strong capability to coping with disturbances in climatic factors, this can be seen in the constant and largely stable low productivity conditions despite large climate variability and also strong cyclical variability with periods of very low and stable NDVI. So vegetation of these areas usually show strong memory effects. This contrasts to areas with high NDVI, such as the river valley and the mountain area, where the river water and the more precipitation can moderate the severe drought and provide better conditions for vegetation growth, yet the growth of vegetation is restricted by the variation in water supply.

In addition, vegetation memory effects in the study area does not show a clear linear relationship with temperature and precipitation, but we can see from the figure (Fig.6b, 6c) that there is an obvious inflection point in the image, which means there a threshold in both the precipitation and temperature effects on memory effects. This might be related to the co-effect of temperature and precipitation on vegetation. For areas in the arid region, altitude usually controls the spatial differentiation of precipitation and temperature, therefore relationship between the memory effects and climatic factors are branded with the influences of altitude on temperature and precipitation. Plain of low altitude is usually characterized by high temperature and scare precipitation, whereas mountain areas are usually characterized by low temperature and abundant precipitation. So, the limiting factor on the growth of vegetation changes gradually from precipitation to temperature along the variation in altitude, which results in vegetation

Peer) reviewing PDF | (2020:11:55104:1:2:NEW 18 Mar 2021) 
370 changes in certain areas are co-affected of temperature and precipitation and the threshold in both the precipitation

371 and temperature effects on memory effects.

\section{Spatial heterogeneity of VSI distribution}

373 VSI reflects the sensitivity of vegetation cover to climate change, and we can identify regions that exhibits

374 amplified responses to climate variability through VSI. While Memory effect measures the capability of vegetation

375 returning to its normal state after suffering the disturbance. Specially, areas with low VSI values showed the largest

376 memory effect (Seddon et al. 2016), which is consistent with our study results (Fig.5 and Fig.7a).The desert plain

377 area in the south of the study area has low sensitivity to climate change and strong vegetation memory effect. When

378 the adverse conditions for vegetation growth are generated due to the vicious climate development or other

379 disturbances in the region, the vegetation will make a hysteresis response to such changes, so that the ecosystem can

380 make timely adjustments to the environmental deterioration. Different types of vegetation respond differently. The

381 main vegetation type is desert meadow, which is a short-lived plant that survives in arid areas by escaping drought

382 (Guo et al. 2004; Lu et al. 2019). The ephemeral plants germinate and grow quickly in spring when the elevated

383 temperature melts the frozen soil or the covering snow and complete their life cycle before the coming of the hot and

384 dry summer. In addition, studies (J.Z. \& H.J. 2015) have shown that the water content of soil at different depths is

385 affected differently by precipitation. Among them, the water content of shallow soil $(0-20 \mathrm{~cm})$ is most affected by

386 precipitation. Desert meadow in arid and semi-arid areas have relatively short rooting system that mainly absorb

387

388

389

390

391

392

393

394

395

396 moisture from shallow soil, so the vegetation changes in this area are more sensitive to precipitation.

In contrast to the desert plain area in the south, the central Irtysh River valley showed higher sensitivity and weaker memory effect. The central river valley area is dominated by herbaceous swamps, which are typical lowlevel swamps, with year-round accumulation of water or drenched soil (H.Y. et al. 2020), and the water supply mainly depends on the Irtysh River. The local vegetation is dominated by perennial plants such as caress and gramineous plants. Many plants have short root systems and mainly absorb shallow soil water, which are highly dependent on soil moisture conditions. Therefore, when the amount of river water decreases, the soil water content of the swamp will also decrease, exerting a hard impact on the growth of herbs. Additionally, TVDI is an index reflecting soil moisture, smaller TVDI indicates that the wetter soil (Sandholt et al. 2002), so the vegetation on the site is more sensitive to TVDI.

Peer) reviewing PDF | (2020:11:55104:1:2:NEW 18 Mar 2021) 
It is worth noting that the northern mountain regions show strong sensitivity to climate change (VSI $>50$ in some

398

399

400

401

402

403

404

405

406

407

408

409

410

411

412

413

414

415

416

417

418

419

420

421

422

423

424

425

426

areas). And the vegetation variation in this area is mainly affected by the combined effects of temperature and precipitation. Compared to the powerful ability of the desert plants in coping the severe drought, temperate steppe in the mountain area is well developed because the elevated altitude relieves both the restrictions of scarce precipitation and high temperature and provides hydrothermal conditions suitable for the grass plants, which makes variations in the coverage of temperate steppe are sensitive to both the precipitation and temperature.

\section{Conclusions}

This study applied a new method and remote sensing datasets of high temporal resolution to quantify the sensitivity and memory effects of vegetation in the Irtysh River, and further reveal the mechanism of vegetation response to climate change at the regional scale. We found that the variation trend of precipitation, temperature and TVDI all indicated that the climate condition of the Irtysh River basin had been greatly improved, and the vegetation coverage also showed overall increasing trend. From the south to the north of the study area, with the change of topographic and geomorphic features, the memory effect of vegetation and its sensitivity to different climatic factors showed obvious spatial heterogeneity. It is mainly manifested in the following aspects, the memory effect of vegetation in the southern desert plain was stronger and the plants there are more sensitive to precipitation, while the herbaceous swamp and broad-leaf forest in the central valley showed weaker memory effect and were more sensitive to TVDI. The temperate steppe in the northern mountain is highly sensitive to climate change and were more affected by the combination of both precipitation and temperature. These results will help us locate different ecological protection environment types more accurately in the future basin management process, and develop optimal adaptive ecological protection strategies to protect this vulnerable ecosystem.

\section{Acknowledgements}

This work was supported by the Xinjiang Tianshan Youth Program (2019Q006), West Light Foundation of Chinese Academy of Sciences (2019-XBQNXZ-A-001) and Science and Technology Service Network Project of Chinese Academy of Sciences (KFJ-STSQYZD-114).

\section{References}

Anav A, and Mariotti A. 2011. Sensitivity of natural vegetation to climate change in the Euro-Mediterranean area. Climate Research 46:277-292. 10.3354/cr00993

Peer] reviewing PDF | (2020:11:55104:1:2:NEW 18 Mar 2021) 
427

428

429

430

431

432

433

434

435

436

437

438

439

440

441

442

443

444

445

446

447

448

449

450

451

452

453

454

455

456

457

458

459

460

461

462

463

464

465

466

467

468

469

470

471

472

473

474

475

476

477

478

479

Atta ur R, and Dawood M. 2017. Spatio-statistical analysis of temperature fluctuation using Mann-Kendall and Sen's slope approach. Climate Dynamics 48:783-797. 10.1007/s00382-016-3110-y

Cai Z, Jonsson P, Jin H, and Eklundh L. 2017. Performance of Smoothing Methods for Reconstructing NDVI TimeSeries and Estimating Vegetation Phenology from MODIS Data. Remote Sensing 9. 10.3390/rs9121271

Chen S, Chen X, Chen W, Su Y, and Li D. 2011. A simple retrieval method of land surface temperature from AMSR-E passive microwave data-A case study over Southern China during the strong snow disaster of 2008. International Journal of Applied Earth Observation and Geoinformation 13:140-151. 10.1016/j.jag.2010.09.007

Christman ZJ, and Rogan J. 2012. Error Propagation in Raster Data Integration: Impacts on Landscape Composition and Configuration. Photogrammetric Engineering and Remote Sensing 78:617-624. 10.14358/pers.78.6.617

Clifford MJ, Cobb NS, and Buenemann M. 2011. Long-Term Tree Cover Dynamics in a Pinyon-Juniper Woodland: Climate-Change-Type Drought Resets Successional Clock. Ecosystems

14:949-962.

Coen MC, Andrews E, Bigi A, Martucci G, Romanens G, Vogt FPA, and Vuilleumier L. 2020. Effects of the prewhitening method, the time granularity, and the time segmentation on the Mann-Kendall trend detection and the associated Sen's slope. Atmospheric Measurement Techniques 13:6945-6964. 10.5194/amt-13-6945-2020

Cramer WP, and Leemans R. 1993. Assessing Impacts of Climate Change on Vegetation Using Climate Classification Systems. Vegetation Dynamics Global Change.

Dash J, Carr AS, and Harris A. 2014. Remote sensing of vegetation cover dynamics and resilience across southern Africa. International journal of applied earth observation geoinformation.

De Keersmaecker W, Lhermitte S, Tits L, Honnay O, Somers B, Coppin PJGE, and Biogeography. 2015. A model quantifying global vegetation resistance and resilience to short-term climate anomalies and their relationship with vegetation cover. 24:539-548.

Deng ZJ, Guan HD, Hutson J, Forster MA, Wang YQ, and Simmons CT. 2017. A vegetation-focused soil-plantatmospheric continuum model to study hydrodynamic soil-plant water relations. Water Resources Research 53:4965-4983. 10.1002/2017wr020467

Fensholt R, Rasmussen K, Nielsen TT, and Mbow C. 2009. Evaluation of earth observation based long term vegetation trends - Intercomparing NDVI time series trend analysis consistency of Sahel from AVHRR GIMMS, Terra MODIS and SPOT VGT data. Remote Sensing of Environment 113:1886-1898. 10.1016/j.rse.2009.04.004

Garcia D. 2010. Robust smoothing of gridded data in one and higher dimensions with missing values. Computational Statistics \& Data Analysis 54:1167-1178. 10.1016/j.csda.2009.09.020

Goward SN, Markham B, Dye DG, Dulaney W, and Yang JL. 1991. NORMALIZED DIFFERENCE VEGETATION INDEX MEASUREMENTS FROM THE ADVANCED VERY HIGH-RESOLUTION RADIOMETER. Remote Sensing of Environment 35:257-277. 10.1016/0034-4257(91)90017-z

Grassini P, You J, Hubbard KG, and Cassman KG. 2010. Soil water recharge in a semi-arid temperate climate of the Central U.S. Great Plains. Agricultural Water Management 97:0-1069.

Guo B, Zhang J, Meng X, Xu T, and Song Y. 2020. Long-term spatio-temporal precipitation variations in China with precipitation surface interpolated by ANUSPLIN. Scientific Reports 10. 10.1038/s41598-019-57078-3

Guo Z, Liang T, and Liu X. 2004. Features of grassland resources and their classified management in Alatai region of Xinjiang. Ying yong sheng tai xue bao = The journal of applied ecology 15:1594-1598.

H.Y. Z, J. Z, D. L, X.X. Q, and H.J. X. 2020. Characteristics and determining factors for ecological stoichiometry of soil carbon, nitrogen, and phosphorus in different marsh wetlands. ARID ZONE RESEARCH 37:618-626.

Han Y, Xuegang C, and Yaqi W. 2013. Dynamic Change of Wetland Landscapes in the Ertix River Basin, Xinjiang during the Period of 1990-2010. ARID ZONE RESEARCH 30:211-218.

$\mathrm{Hu}$ L, Brunsell NA, Monaghan AJ, Barlage M, and Wilhelmi OV. 2014. How can we use MODIS land surface temperature to validate long-term urban model simulations? Journal of Geophysical Research-Atmospheres 119:3185-3201. 10.1002/2013jd021101

Huang F, Xia Z, Guo L, and Yang F. 2013a. Climate change detection and annual extreme temperature analysis of the Irtysh Basin. Theoretical and Applied Climatology 111:465-470. 10.1007/s00704-012-0676-0

Huang F, Xia Z, Li F, Guo L, and Yang F. 2012. Hydrological Changes of the Irtysh River and the Possible Causes. Water Resources Management 26:3195-3208. 10.1007/s11269-012-0067-4

Huang F, Xia ZQ, Guo LD, and Yang FC. 2013b. Climate change detection and annual extreme temperature analysis of the Irtysh Basin. Theoretical and Applied Climatology 111:465-470. 10.1007/s00704-012-0676-0

Peer) reviewing PDF | (2020:11:55104:1:2:NEW 18 Mar 2021) 
480

481

482

483

484

485

486

487

488

489

490

491

492

493

494

495

496

497

498

499

500

501

502

503

504

505

506

507

508

509

510

511

512

513

514

515

516

517

518

519

520

521

522

523

524

525

526

527

528

529

530

531

532

Huete, and Alfredo. 2016. Ecology: Vegetation\"s responses to climate variability. Nature.

Huete A. 2016. ECOLOGY Vegetation's responses to climate variability. Nature 531:181-182. 10.1038/nature17301

J.Z. L, and H.J. M. 2015. Response of vegetation and soil to precipitation in the desert area in the middle reaches of Heihe River Practical Forestry Technology:8-10.

Jarvis $\mathrm{CH}$, and Stuart N. 2001. A comparison among strategies for interpolating maximum and minimum daily air temperatures. Part I: the selection of "guiding" topographic and land cover variables. Journal of Applied Meteorology 40:1060-1074. 10.1175/1520-0450(2001)040<1060:Acasfi>2.0.Co;2

Jeong S-J, Ho C-H, Gim H-J, and Brown ME. 2011. Phenology shifts at start vs. end of growing season in temperate vegetation over the Northern Hemisphere for the period 1982-2008. Global Change Biology 17:2385-2399. 10.1111/j.1365-2486.2011.02397.x

Jiang L, Jiapaer G, Bao A, Guo H, and Ndayisaba F. 2017. Vegetation dynamics and responses to climate change and human activities in Central Asia. Science of the Total Environment 599:967-980. 10.1016/j.scitotenv.2017.05.012

$\mathrm{Ju}$ B, Ye W, and Hu d. 2015. Variation characteristics and trend of precipitation in Irtysh River basin of Xinjiang. Journal of Water Resources \& Water Engineering:115-119.

Kastens JH, Kastens TL, Kastens DLA, Price KP, Martinko EA, and Lee RY. 2005. Image masking for crop yield forecasting using AVHRR NDVI time series imagery. Remote Sensing of Environment 99:341-356. 10.1016/j.rse.2005.09.010

Kendall MG. 1990. Rank correlation methods. British Journal of Psychology 25:86-91.

Kerr JT, and Ostrovsky M. 2003. From space to species: ecological applications for remote sensing. Trends in Ecology $\mathcal{E}$ Evolution 18:299-305. 10.1016/s0169-5347(03)00071-5

Khan B, Hayes LWB, and Cracknell AP. 1995. THE EFFECTS OF HIGHER-ORDER RESAMPLING ON AVHRR DATA. International Journal of Remote Sensing 16:147-163. 10.1080/01431169508954377

Lhermitte S, Verbesselt J, Verstraeten WW, Veraverbeke S, and Coppin P. 2010. Assessing intra-annual vegetation regrowth after fire using the pixel based regeneration index \%J ISPRS Journal of Photogrammetry and Remote Sensing. 66.

Li D, Wu S, Liu L, Zhang Y, and Li S. 2018. Vulnerability of the global terrestrial ecosystems to climate change. Global Change Biology 24:4095-4106. 10.1111/gcb.14327

Li Z, Ma W, Liang C, Liu Z, Wang W, and Wang L. 2015. - Long-term vegetation dynamics driven by climatic variations in the Inner Mongolia grassland: findings from 30-year monitoring. - 30:- 1711.

Liu ZY, Notaro M, Kutzbach J, and Liu N. 2006. Assessing global vegetation-climate feedbacks from observations. Journal of Climate 19:787-814. 10.1175/jcli3658.1

Los SO, Weedon GP, North PRJ, Kaduk JD, Taylor CM, and Cox PM. 2006. An observation-based estimate of the strength of rainfall-vegetation interactions in the Sahel. Geophysical Research Letters 33. 10.1029/2006gl027065

Lu K-Q, Li M, Wang G-H, Xu L-S, Ferguson DK, Trivedi A, Xuan J, Feng Y, Li J-F, Xie G, Yao Y-F, and Wang Y-F. 2019. New pollen classification of Chenopodiaceae for exploring and tracing desert vegetation evolution in eastern arid central Asia. Journal of Systematics and Evolution 57:190-199. 10.1111/jse.12462

Ludeke MKB, Ramge PH, and Kohlmaier GH. 1996. The use of satellite NDVI data for the validation of global vegetation phenology models: Application to the Frankfurt Biosphere Model. Ecological Modelling 91:255-270. 10.1016/0304-3800(95)00192-1

Mann HB. 1945. Non-Parametric Test Against Trend. Econometrica 13:245-259.

Maselli F, Papale D, Chiesi M, Matteucci G, Angeli L, Raschi A, and Seufert G. 2014. Operational monitoring of daily evapotranspiration by the combination of MODIS NDVI and ground meteorological data: Application and evaluation in Central Italy. Remote Sensing of Environment 152:279-290. 10.1016/j.rse.2014.06.021

Mearns LO, Rosenzweig C, and Goldberg R. 1997. Mean and variance change in climate scenarios: Methods, agricultural applications, and measures of uncertainty. Climatic Change 35:367-396. 10.1023/a:1005358130291

Mkhabela MS, Bullock P, Raj S, Wang S, and Yang Y. 2011. Crop yield forecasting on the Canadian Prairies using MODIS NDVI data. Agricultural and Forest Meteorology 151:385-393. 10.1016/j.agrformet.2010.11.012

Moulin S, Kergoat L, Viovy N, and Dedieu G. 1997. Global-scale assessment of vegetation phenology using NOAA/AVHRR satellite measurements. Journal of Climate 10:1154-1170. 10.1175/15200442(1997)010<1154:Gsaovp>2.0.Co;2

Navarro A, Garcia-Ortega E, Merino A, Luis Sanchez J, and Tapiador FJ. 2020. Orographic biases in IMERG precipitation estimates in the Ebro River basin (Spain): The effects of rain gauge density and altitude. Atmospheric Research 244. 10.1016/j.atmosres.2020.105068

Peer] reviewing PDF | (2020:11:55104:1:2:NEW 18 Mar 2021) 
533

534

535

536

537

538

539

540

541

542

543

544

545

546

547

548

549

550

551

552

553

554

555

556

557

558

559

560

561

562

563

564

565

566

567

568

569

570

571

572

573

574

575

576

577

578

579

580

581

582

583
Oba G, Post E, and Stenseth NC. 2001. Sub-saharan desertification and productivity are linked to hemispheric climate variability. Global Change Biology 7:241-246. 10.1046/j.1365-2486.2001.00405.x

Pan Z, Hu Y, and Cao B. 2017. - Construction of smooth daily remote sensing time series data: a higher spatiotemporal resolution perspective. - 2.

Pettorelli N, Laurance WF, O'Brien TG, Wegmann M, Nagendra H, and Turner W. 2014. Satellite remote sensing for applied ecologists: opportunities and challenges. Journal of Applied Ecology 51:839-848. 10.1111/13652664.12261

Piao S, Mohammat A, Fang J, Cai Q, and Feng J. 2006. NDVI-based increase in growth of temperate grasslands and its responses to climate changes in China. Global Environmental Change-Human and Policy Dimensions 16:340-348. 10.1016/j.gloenvcha.2006.02.002

QiangJi L, and Wu S. 2017. Variation Characteristics of Diurnal Temperature and Influence Factors of Irtysh River in Xinjiang. Journal of Soil and Water Conservation 031:351-356.

Rotenberg E, and Yakir D. 2010. Contribution of Semi-Arid Forests to the Climate System. Science 327:451-454. 10.1126/science.1179998

Safriel U, Adeel Z, Niemeijer D, Puigdefabregas J, White R, Lal R, Winslow M, Ziedler J, Prince S, Archer E, King C, Shapiro B, Wessels K, Nielsen T, Portnov B, Becker-Reshef I, Thonnell J, Lachman E, and McNab D. 2020.662.

Sandholt I, Rasmussen K, and Andersen J. 2002. A simple interpretation of the surface temperature/vegetation index space for assessment of surface moisture status. Remote Sensing of Environment 79:213-224. 10.1016/s00344257(01)00274-7

Sarkar S, and Kafatos M. 2004. Interannual variability of vegetation over the Indian sub-continent and its relation to the different meteorological parameters. Remote Sensing of Environment 90:268-280. 10.1016/j.rse.2004.01.003

Schloss AL, Kicklighter DW, Kaduk J, Wittenberg U, and Participants Potsdam NPPMI. 1999. Comparing global models of terrestrial net primary productivity (NPP): comparison of NPP to climate and the Normalized Difference Vegetation Index (NDVI). Global Change Biology 5:25-34. 10.1046/j.1365-2486.1999.00004.x

Schwinning S, Sala OE, Loik ME, and Ehleringer JR. 2004. Thresholds, memory, and seasonality: understanding pulse dynamics in arid/semi-arid ecosystems. Oecologia 141:191-193. 10.1007/s00442-004-1683-3

Seddon AWR, Macias-Fauria M, Long PR, Benz D, and Willis KJ. 2016. Sensitivity of global terrestrial ecosystems to climate variability. Nature 531:229-+. 10.1038/nature16986

Shen Y, Wang G, Su H, Han M, Gao Q, and Wang S. 2007. Hydrological Processes Responding to Climate Warming in the Upper Reaches of Kelan River Basin with Snow-dominated of the Altay Mountains Region, Xinjiang, China. JOURNAL OF GLACIOLOGY AND GEOCRYOLOGY 029:845-854.

Simoniello T, Lanfredi M, Liberti M, Coppola R, and Macchiato M. 2008. Estimation of vegetation cover resilience from satellite time series. Hydrology and Earth System Sciences 12:1053-1064. 10.5194/hess-12-1053-2008

Slayback DA, Pinzon JE, Los SO, and Tucker CJ. 2003. Northern hemisphere photosynthetic trends 1982-99. Global Change Biology 9:1-15. 10.1046/j.1365-2486.2003.00507.x

Sun G, Wang C, Chang L, Wu Y, Li L, and Jin Z. 2018. Effects of feedback regulation on vegetation patterns in semiarid environments. Applied Mathematical Modelling 61:200-215. 10.1016/j.apm.2018.04.010

Thiam AK. 2003. The causes and spatial pattern of land degradation risk in southern Mauritania using multitemporal AVHRR-NDVI imagery and field data. Land Degradation \& Development 14:133-142. 10.1002/ldr.533

Thomas CD, Cameron A, Green RE, Bakkenes M, Beaumont LJ, Collingham YC, Erasmus BFN, de Siqueira MF, Grainger A, Hannah L, Hughes L, Huntley B, van Jaarsveld AS, Midgley GF, Miles L, Ortega-Huerta MA, Peterson AT, Phillips OL, and Williams SE. 2004. Extinction risk from climate change. Nature 427:145-148. 10.1038/nature02121

Tilman D. 1996. Biodiversity: Population versus ecosystem stability. Ecology 77:350-363. 10.2307/2265614

Weng QH. 2002. Land use change analysis in the Zhujiang Delta of China using satellite remote sensing, GIS and stochastic modelling. Journal of Environmental Management 64:273-284. 10.1006/jema.2001.0509

Willis KJ, Jeffers ES, and Tovar C. 2018. What makes a terrestrial ecosystem resilient? A complex set of biotic and abiotic factors determines the resilience of an ecosystem. Science 359:988-989. 10.1126/science.aar5439

Yang F, Xia Z, Yu L, and Guo L. 2012. Calculation and Analysis of the Instream Ecological Flow for the Irtysh River. In: Zhou B, ed. 2012 International Conference on Modern Hydraulic Engineering, 438-441.

Peer] reviewing PDF | (2020:11:55104:1:2:NEW 18 Mar 2021) 
584 585

586

587

588

589

590

591

592

593

594

595

596

597

598

599

600

601

602
Yang J, and Wang Y. 2011. Estimating evapotranspiration fraction by modeling two-dimensional space of NDVI/albedo and day-night land surface temperature difference: A comparative study. Advances in Water Resources 34:512-518. 10.1016/j.advwatres.2011.01.006

Yang Y, Zhao C, Han M, Li Y, and Yang R. 2015. Temporal Patterns of Shrub Vegetation and Variation with Precipitation in Gurbantunggut Desert, Central Asia. Advances in Meteorology 2015. 10.1155/2015/157245

Yao C, Zhang Z, and Wang X. 2004. Evaluating Soil Moisture Status in Xinjiang Using the Temperature Vegetation Dryness Index (TVDI). REMOTE SENSING TECHNOLOGY AND APPLICATION 19:473-479.

Ye G, and Bai Y. 2014. Study On the Ecological Flow in the Middle Reaches of Irtysh Rivers. Third International Conference on Agro-Geoinformatics, 128-131.

You N, Meng J, and Zhu L. 2018. Sensitivity and resilience of ecosystems to climate variability in the semi-arid to hyper-arid areas of Northern China: a case study in the Heihe River Basin. Ecological Research 33:161-174. 10.1007/s11284-017-1543-3

Zhang X. 2015. Reconstruction of a complete global time series of daily vegetation index trajectory from long-term AVHRR data. Remote Sensing of Environment 156:457-472. 10.1016/j.rse.2014.10.012

Zhao Y, Zhu J, and Xu Y. 2014. Establishment and assessment of the grid precipitation datasets in China for recent 50 years. Journal of the Meteorological Sciences 34:414-420.

Zhu Y, Zhang J, Zhang Y, Qin S, Shao Y, and Gao YJC. 2019. Responses of vegetation to climatic variations in the desert region of northern China. 175:27-36. 


\section{Table $\mathbf{1}$ (on next page)}

Interpretation of the coefficients in the AR1 multiple linear regression approach

Interpretation of the coefficients in the AR1 multiple linear regression approach 


\section{Table 1}

2 Interpretation of the coefficients in the AR1 multiple linear regression approach

\begin{tabular}{|c|c|c|c|}
\hline Coefficient & Implication & Meaning of absolute value & Meaning of sign \\
\hline$\alpha$ & $\begin{array}{l}\text { Revealing } r \text { the } \\
\text { potential influence of } \\
\text { memory reffects } \\
\text { driving vegetation } \\
\text { dynamics. }\end{array}$ & $\begin{array}{l}\text { A large absolute value indicates low } \\
\text { resilience, which means that vegetation } \\
\text { slowly recovers from previous } \\
\text { disturbance. }\end{array}$ & $\begin{array}{l}\text { Positive value of } \delta \text { shows NDVI is similar } \\
\text { to the previous anomaly. } \\
\text { Negative value of } \delta \text { shows NDVI is similar } \\
\text { to the previous anomaly but with the } \\
\text { opposite trend. }\end{array}$ \\
\hline$\beta / \gamma / \delta$ & $\begin{array}{l}\text { Climatic sensitivity } \\
\text { index denoting the } \\
\text { magnitude of } \\
\text { immediate response } \\
\text { of vegetation to the } \\
\text { contemporary } \\
\text { variation in climate } \\
\text { variable. }\end{array}$ & $\begin{array}{l}\begin{array}{l}\text { Large absolute values indicate low } \\
\text { resistance } \\
\text { temperature/precipitation/TVDI. }\end{array} \\
\text { to }\end{array}$ & $\begin{array}{l}\text { Positive } \\
\text { temperature/precipitation/TVDI than } \\
\text { average induces a positive NDVI response } \\
\text { (higher NDVI). } \\
\text { Negative Lower } \\
\text { temperature/precipitation/TVDI than } \\
\text { average induces a negative NDVI } \\
\text { response (lower NDVI). }\end{array}$ \\
\hline
\end{tabular}


Figure 1

Overview of the Irtysh River basin

Overview of the Irtysh River basin

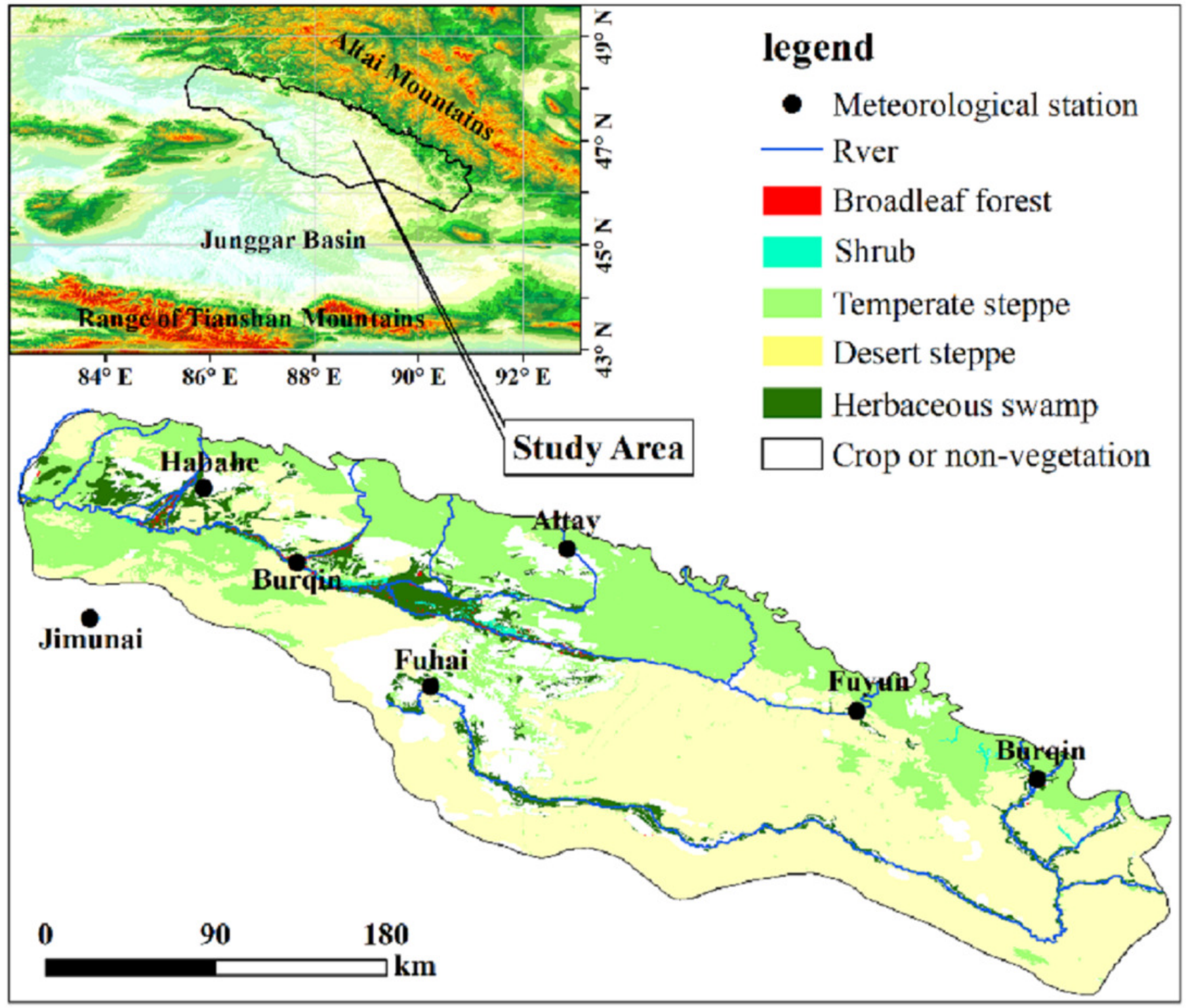


Figure 2

Distribution map of annual average NDVI levels, NDVI change trend Zc value and change rate $\beta$ value

(A) Distribution map of annual average NDVI levels in the study area from 2000 to 2018 and Spatial distribution of variance in vegetation cover; (B) NDVI change trend Zc value and (C) change rate $\beta$ value spatial distribution map. Characterizing change trend of each vegetated pixel in the study area. 

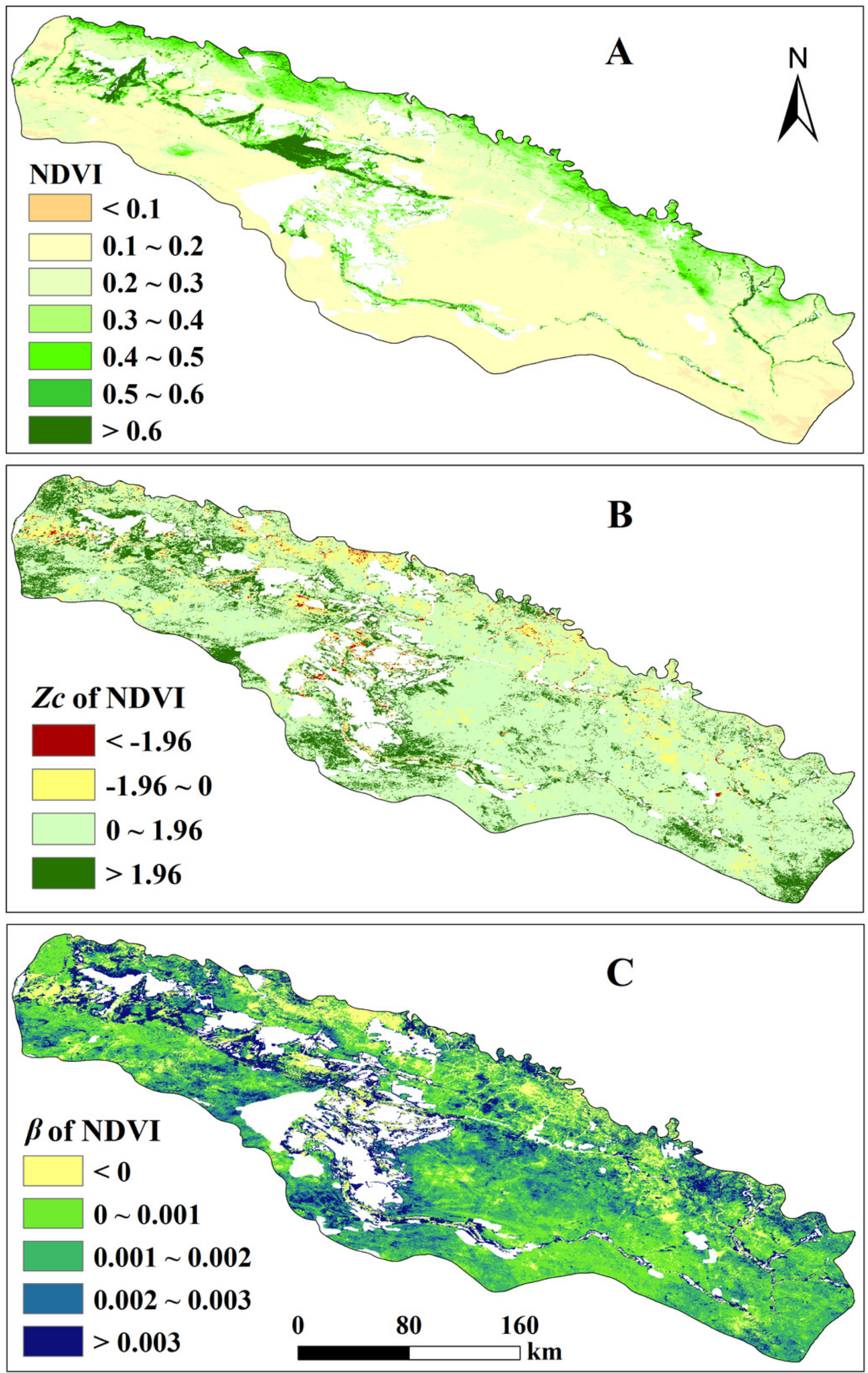
Figure 3

Interannual variation curve of overall NDVI in the study area from 2000 to 2018.

Interannual variation curve of overall NDVI in the study area from 2000 to 2018.

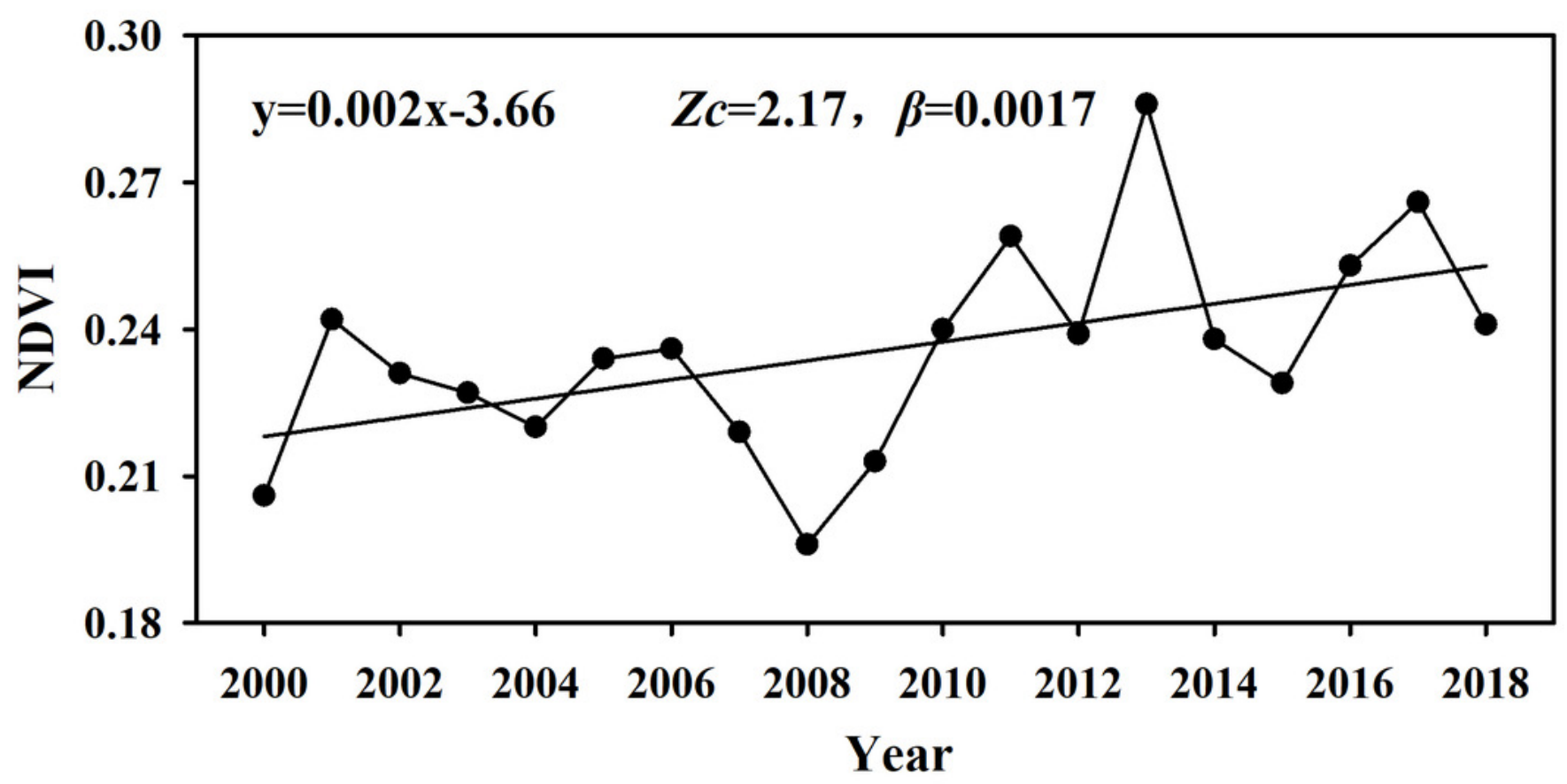


Figure 4

Interannual variation curves of overall precipitation, temperature, and TVDI in the study area from the period 2000-2018.

Interannual variation curves of overall precipitation $(A)$, temperature $(B)$, and TVDI $(C)$ in the study area from the period 2000-2018. 

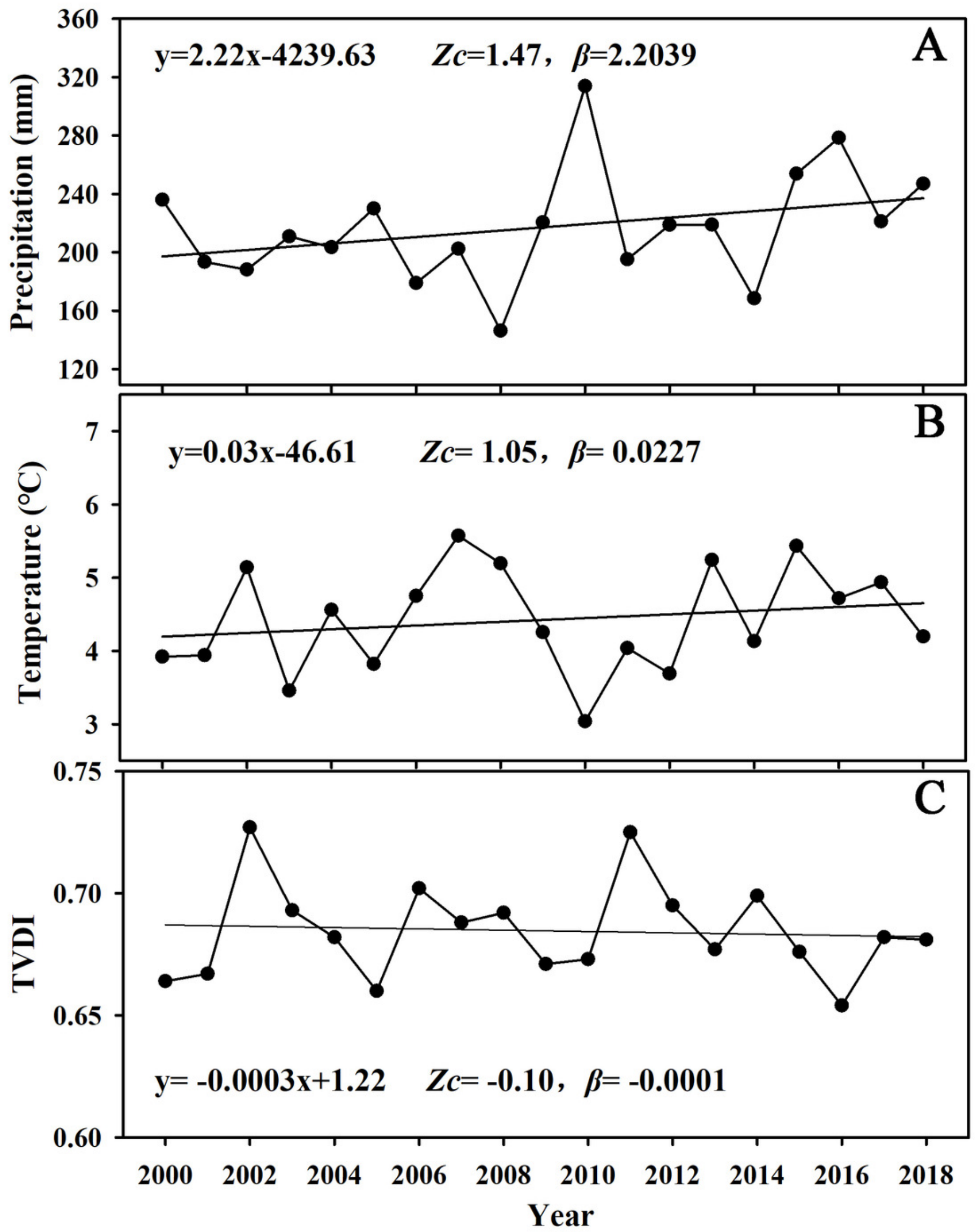


\section{Figure 5}

Spatial distribution of t-1 (AR1) coefficient weight

Spatial distribution of t-1 (AR1) coefficient weight (that is, coefficient $\alpha$ ) from monthly multiple regression between vegetation cover (defined as NDVI), vegetation cover at $\mathrm{t}-1$, and three climatic variables. Characterizing the memory effects of vegetation cover in the Irtysh River basin during 2000-2018.

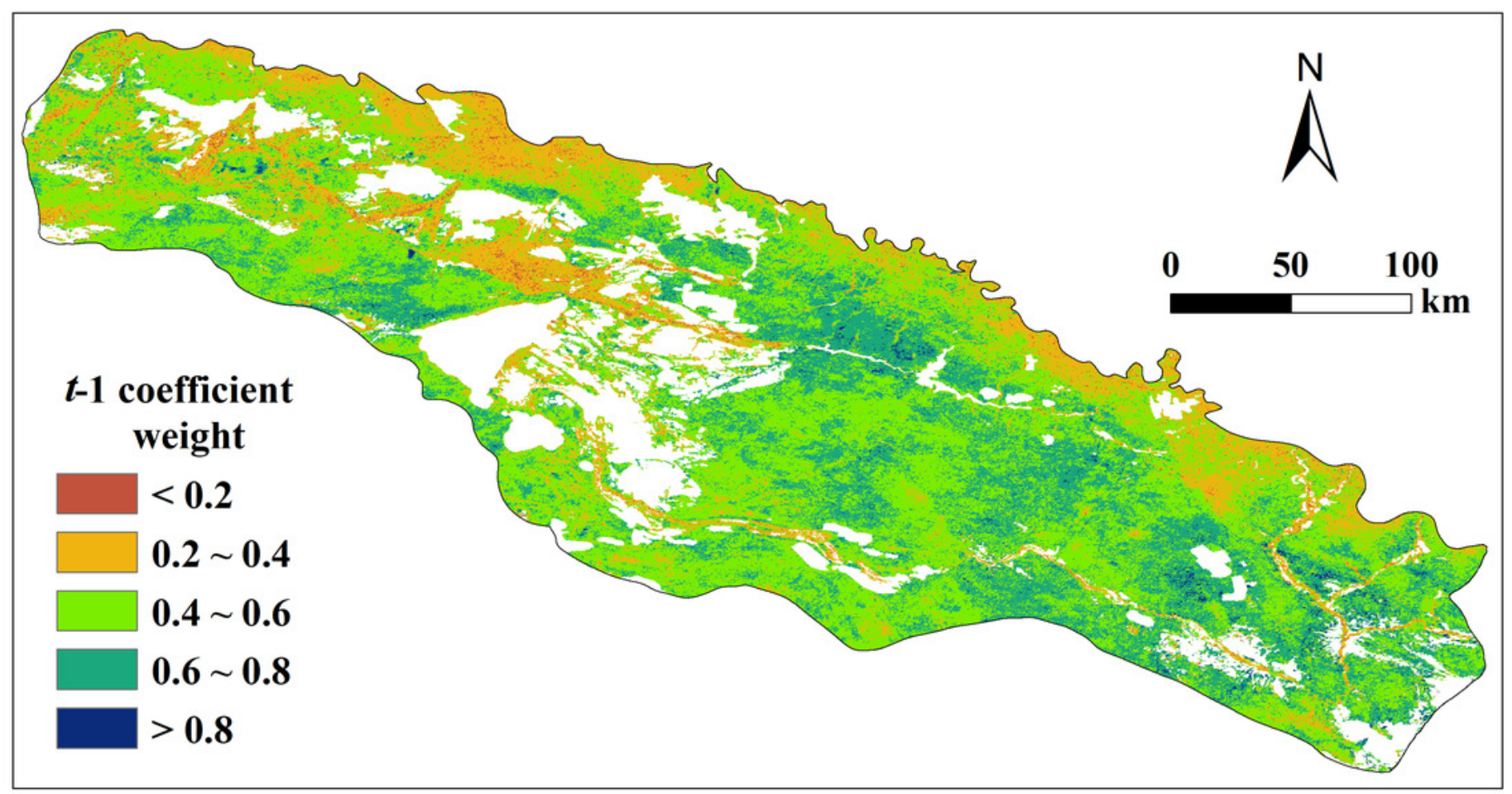


Figure 6

Scatter plots of $\alpha$ (t-1 coefficient weight) along mean growing season climatic factors

Correlations between $\alpha$ (t-1 coefficient weight) and mean growing season (A)NDVI,

(B)precipitation, (C)temperature, (D)TVDI in the Irtysh River basin during 2000-2018. The green curves indicate the fitted regression lines.
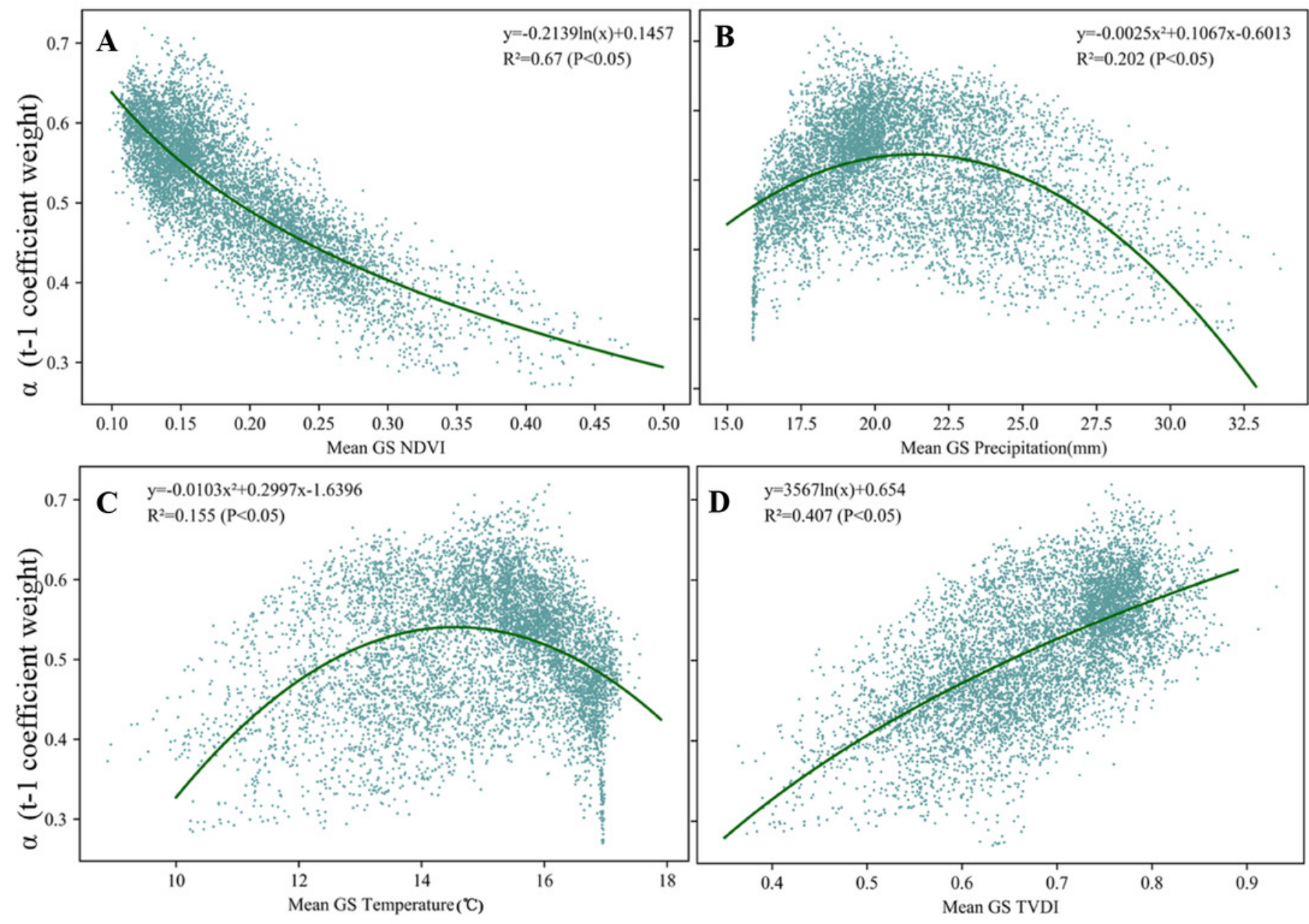


\section{Figure 7}

Distribution of Vegetation sensitivity index (VSI) in Irtysh River basin during 2000-2018

(A) Spatial distribution of Vegetation sensitivity index (VSI) in Irtysh River basin during 2000-2018. The index ranges from 0(low sensitivity) to 100 (high sensitivity). (B) VSI distribution histogram, insert panel of violin plot shows the frequency distribution of pixel VSI values. 

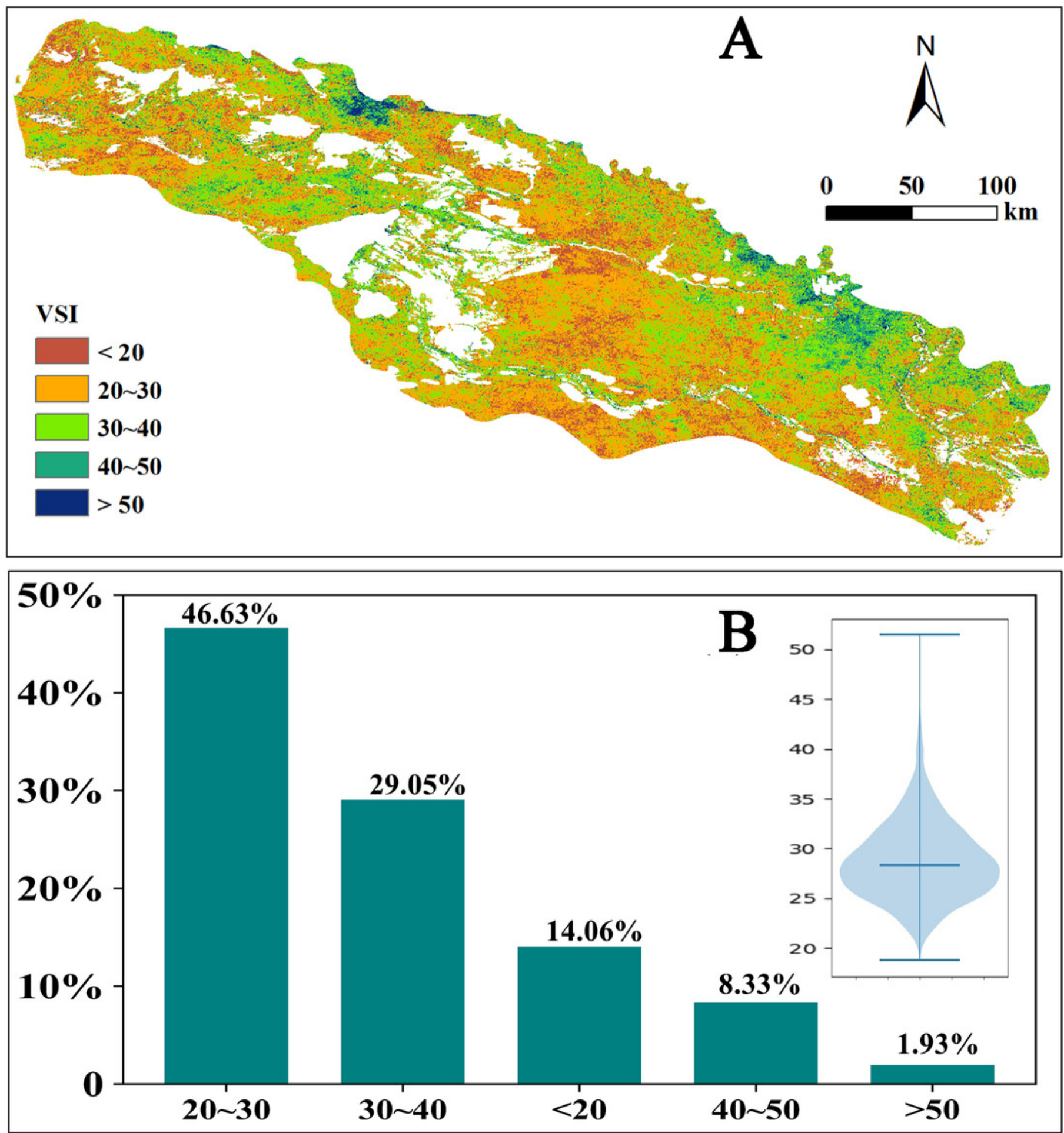


\section{Figure 8}

RGB composite of climate weights

RGB composite of climate weights from monthly multiple regression between vegetation cover (defined as NDVI), vegetation cover at t-1, and three climatic variables. Notably, temperature, red; TVDI, green; and precipitation, blue.

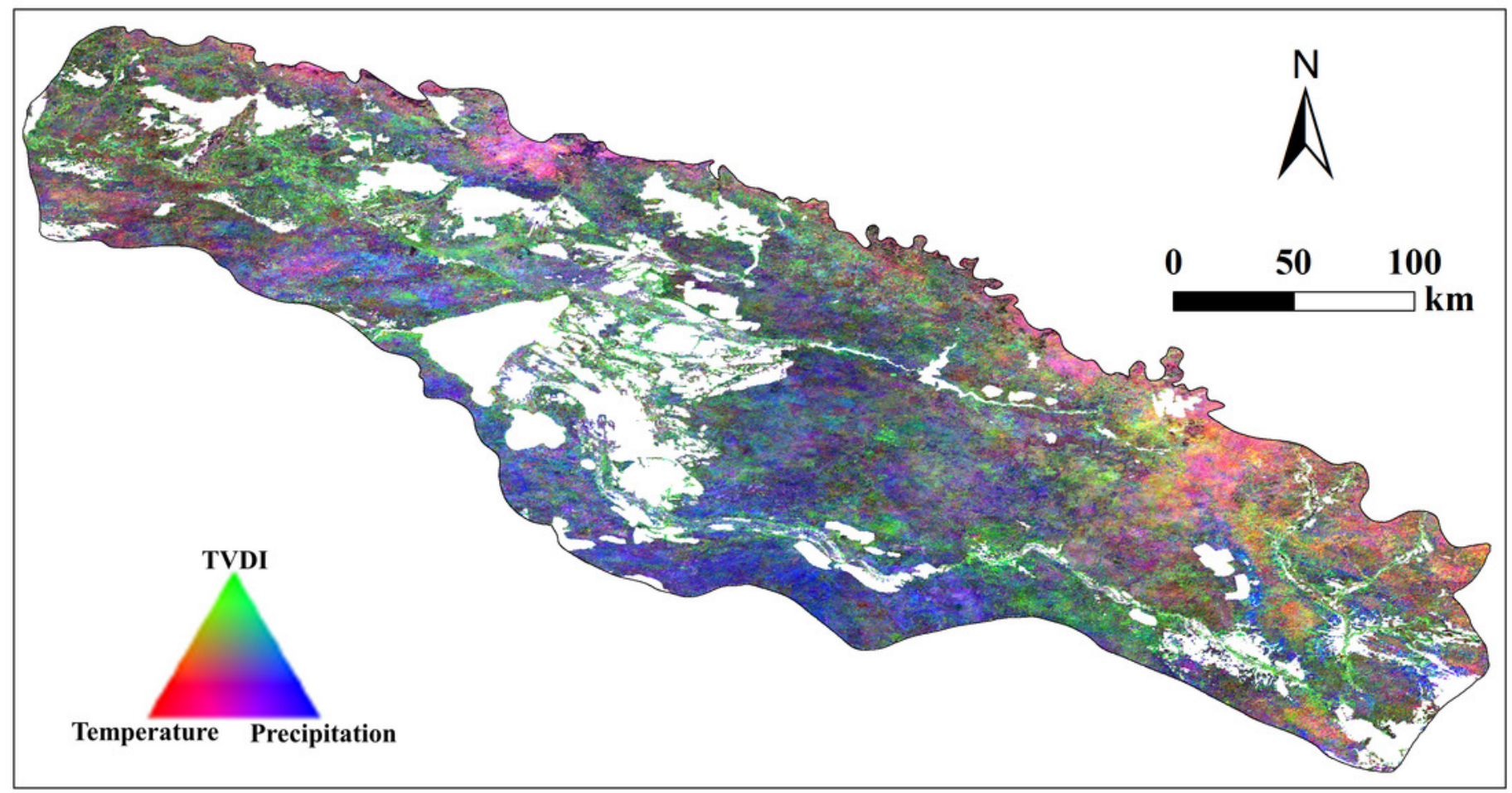

